\title{
NEUROPROTECTION TO COUNTERACT GLAUCOMATOUS DEGENERATION OF RETINA; THE USE OF CITICOLINE
}

\author{
MILENA KOZERA* and MAREK RĘKAS
}

Department of Ophthalmology of the Military Institute of Medicine in Warsaw, Poland

\begin{abstract}
Glaucoma is a chronic degenerative disease affecting the optic nerve that causes a loss of retinal ganglion cells and their axons. Glaucomatous neuropathy constitutes a worldwide health problem. Every ophthalmologist working at a hospital or at an outpatient clinic sees patients with glaucoma, and thus information about the pathomechanisms responsible for its development, about its treatment and about new therapeutic options constitutes valuable knowledge for all ophthalmology practitioners. It is widely known that the better the mechanisms of disease development are known, the easier it is to effectively inhibit disease progression. Therefore, researchers are continuing their studies on pathophysiology and effective treatment, which have been moving from the macroscopic to the microscopic level as new methods become available. And thus, over years of conducted studies, the neuroprotective effect of citicoline was noted. Known to neurologists, this substance is now entering the pharmacological world of ophthalmologists. This article discusses the role and possibilities of neuroprotective treatment of glaucoma, emphasising the scientifically proven effects of citicoline, which seems to be a new trend supporting the drug treatment used to date.
\end{abstract}

Keywords: citicoline, primary open-angle glaucoma (POAG), neuroprotection

Glaucoma, which is one of the principal causes of irreversible blindness in the world (1), represents a serious public health problem. The global number of glaucoma patients was 44 million people in 2013, and this number is predicted to increase to 53 million by 2020 , which is associated with the general trend of population ageing (2). The global percentage of glaucoma patients in the population is $1-2 \%$, and in the group of persons above 70 years of age, it is up to $5 \%$ (2), three-fourths of which $(74 \%)$ are cases of primary open-angle glaucoma (POAG) (3).

Glaucoma is a type of degenerative neuropathy characterised by loss of retinal ganglion cells (RGCs) with subsequent visual field defects (1). Although high intraocular pressure (IOP) is the most important risk factor of the disease's development, it is not necessary for the occurrence of glaucomatous neuropathy (2). The benefits of lowering IOP with respect to inhibition of primary open-angle glaucoma progression have been definitively proven. Nevertheless, the estimated risk of monocular visual defect in patients with POAG at a level of $27 \%$ was higher than previously expected (3). Therefore, IOP reduction may not be sufficient to limit the disease in a certain group of patients with diagnosed glaucoma. Alternative treatment methods, as well as neuroprotection, are considered in such cases.

Neuroprotection to counteract neurodegeneration

Neuroprotection means measures aimed to protect nerve cells from damage and elimination (4). In the context of glaucomatous neuropathy, the objective of neuroprotective treatment is to reduce risk factors that lead to early activation of the cascade of processes whose ultimate outcome is death of retinal ganglion cells (5). In glaucoma, ganglion and glial cells die mainly due to the process called apoptosis, i.e. "programmed cell death". Under normal conditions, a cell constantly receives information about how it should function from its environment. This is important from the perspective of tissue homeostasis. On one hand, the cell may receive a signal to divide into two and multiply, and on the other hand, if the cell is damaged, it may receive a signal to undergo apoptosis in order to eliminate the pathologically changed tissue. In such a case, the cell produces enzymes with which it may "digest" itself, leaving only small apoptotic bodies that subsequently undergo phagocytosis (6).

The death of ganglion cells whose axons form the optic nerve is caused by neuronal damage as a

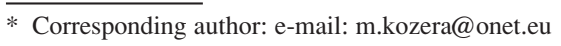


result of disturbed axoplasmic transport, hypoxia, effects of local inflammatory mediators (i.e. glutamate, nitric oxide or endothelin), deprivation of neurotrophic factors or mitochondrial dysfunction (7, 8). An important fact in the analysis of glaucomatous neuropathy is the integrity of the ganglion cell - lateral geniculate body - visual cortex system (9, 10). Retinal ganglion cells are the first to die, and it is at the retinal level where the initial changes occur. Nevertheless, the disease spreads to higher levels of the nervous system. The correlation between reduced sensitivity of the retina in visual field examination (MD - mean deviation) and increased latency of waves in visual evoked potentials examination is clinically apparent (11). And thus the MD indicator used in everyday practice may reflect the damage to cells not only at the retinal level but also at the epiretinal level (12). Similarity in the pathogenesis of the glaucomatous process to such central nervous system diseases as Alzheimer's disease indicates an important aspect of glaucoma consideration in the context of neurodegeneration.

Currently, IOP is the only modifiable risk factor of glaucoma and basically the focus of treatment. Nevertheless, owing to recent advances in the understanding of the neurodegenerative process in glaucoma, neuroprotective treatment has been proposed as a different approach to improved management of this condition.

\section{Neuroprotection to counteract excitotoxicity}

Glutamate is the main stimulating neurotransmitter in the brain and retina (12) in vitro (13) and in vivo (14). Studies where peripheral cells of the retina's internal layers were exposed to glutamate evidenced its toxic effect on the retina, with particular susceptibility of ganglion cells. Under physiological conditions, where the level of glutamate is normal, it interacts with N-methyl-D-aspartate (NMDA) receptors in a synchronised manner owing to the efficient functioning of homeostatic mechanisms that prevent overexpression of those receptors (15). On the other hand, excitotoxicity is a result of excessive accumulation of glutamate along with overstimulation of receptors. Under such conditions, increased intracellular calcium influx occurs, which activates the complex cascade of cellular apoptosis (16).

In experimental models, an increased level of glutamate was evidenced after a sudden increase in intraocular pressure (17). Moreover, the composition of vitreous fluid was analysed in animal models (dogs, monkeys) and in human eyes with experimentally induced glaucoma, which confirmed the high intraocular level of this neurotransmitter (18, 19). The results of these and other studies highlighted the important role of excitotoxicity in the mechanism of glaucomatous neuropathy development. A similar pathogenic mechanism was evidenced in a wide range of neurological disorders, including Alzheimer's disease (20-22). In response to these observations, inhibition of glutamate activity through modulation of NMDA-type receptors is reported to be an important strategy in neuroprotection. For this purpose, a number of analyses of compounds acting as NMDA receptor antagonists have been performed. An example is a memantine, approved by the Food and Drug Administration (FDA) for the treatment of moderate-to-severe Alzheimer's disease. Experiments with this compound in studies on neuroprotection in glaucoma did not demonstrate a significant effect inhibiting disease progression $(23,26)$ despite the hopes initially placed in memantine during preclinical studies $(24,25)$.

As for the new NMDA antagonists, studies are currently underway with regard to the efficacy of bis(7)-tacrine in glaucoma neuroprotection. The compound appeared to cause a more potent neuroprotective effect in a study in cultured RGC (27). than memantine, extended by concomitant inhibition of acetylcholinesterase $(28,29)$. and nitric oxide synthase (30), in addition to the NMDA receptor blocking function. However, the results of those clinical trials will not be available any time soon. Amantadine may prove to be another potential neuroprotective substance, which acts by decreasing NMDA activity (31).

\section{Calcium channel blockers}

Calcium influx into the cell is a physiological stimulus for initiation of the process of cellular apoptosis. Therefore, calcium channel blockers seem to constitute a reasonable alternative in glaucoma neuroprotection. Their targeted effect of blocking calcium-sensing receptors reduces the possibility of initiation of the cascade of processes leading to cell death and additionally improves local blood flow in hypoxic tissues by inducing vasodilation (32). In a study in rabbits, systemically administered $2 \%$ flunarizine improved retinal blood supply under retinal hypoxia conditions caused by high intraocular pressure and lowered the IOP (33). On the other hand, iganidipine, nimodipine and lomerizine, respectively, increased the viability of rat RGCs under oxygen deficiency conditions (34). In randomised clinical trials (35-37), evidence was presented that brovincamine and nilvadipine, sub- 
stances with high blood-brain barrier permeability, improve visual field defects and ocular circulation in a group of patients with normal tension glaucoma (NTG) and additionally diminish the rate of deterioration in visual field sensitivity.

Nevertheless, calcium channel blockers also appeared to cause some negative effects in glaucoma treatment. Despite the proven increase in blood flow, they may interfere with autoregulation of ocular perfusion in persons with ocular hypertension, which contributes to the development of glaucomatous neuropathy (38). By lowering systemic blood pressure, calcium channel blockers used in the treatment of arterial hypertension in persons with coexisting elevated IOP adversely affect the perfusion pressure in the eye and cause vascular dysregulation (39), which results in impaired blood flow in the retina and through the optic nerve disc and in hypoxia and ischaemia, which cause damage to these structures.

\section{Neuroprotection to counteract neurotrophic fac- tors and axoplasmic transport}

Neurotrophic factors play an important role in the maintenance of normal neuronal functioning, both through improved viability of nerve cells as well as through regulation of the processes of their differentiation, growth and regeneration. These factors are transported in both directions to nerve cells inside the nerve fibre, in a process called axoplasmic flow. High intraocular pressure or decreased blood flow (40), or optic nerve axotomy (41), lead to disturbances in the axoplasmic flow. This results in the lack of supply of neurotrophic factors, i.e. the absence of information for the cell about how it should function. This is one of the underlying factors that initiate the process of cellular apoptosis (42, 43). Experimental studies demonstrated a significant role of brain-derived neurotrophic factor (BDNF) in the protection of retinal ganglion cells (43-45). Its trophic effects are regulated, e.g. by the presence of the transmembrane tyrosine kinase receptor (TrkB). Changes in the distribution of the BDNF and TrkB receptors in optic nerve axons were evidenced in acute and chronic experimental glaucoma in an animal model (43). Furthermore, the selective effect of BDNF on the mechanisms responsible for the survival of optic nerve neurons was demonstrated (46). This is why interference with the supply of BDNF to RGCs could be considered a factor causing glaucomatous damage (42). Numerous experimental studies also demonstrated a protective effect of intravitreal injection of BDNF on retinal ganglion cells in an animal model (46-48).
A number of other neurotrophic factors (NTFs), such as ciliary neurotrophic factor (CNTF) (49), nerve growth factor (NGF) (50) and glial-derived neurotrophic factor (GDNF) (51) also exert a protective effect on RGCs. In addition, such trophic factors and cytokines as artemin, basic fibroblast growth factor, interleukin-6 or erythropoietin may play a role in neuroprotection (52).

Among the NTFs listed above, inhibition of visual loss progression was evidenced in a phase-2 study of geographic atrophy in which an encapsulated CNTF-secreting implant was used (53). Furthermore, a protective effect of CNTF on RGCs after optic nerve axotomy (54). as well as in apoptosis induced by nitric oxide (NO) was demonstrated (55). In animal model studies, a neurotrophic factor was administered by intravitreal injection (54), as drops (56) and with the use of viral vectors (57).

There is no doubt as to the participation of neurotrophic factors in the pathogenesis of the glaucomatous process. On the other hand, it is challenging to develop the most effective and durable route of NTF administration. The blood-retinal barrier, which prevents the passage of large proteins into the retina, limits systemic administration of NTFs. An alternative delivery route for purified recombinant NTFs is an injection into the vitreous chamber. Nevertheless, it is an invasive route, which may be difficult in clinical practice in the case of such a chronic disease as glaucoma. Integration of neurotrophic factors in the form of implants is one possible method of long-term delivery of such agents. In animal models, trophic factors were also delivered through viral vectors, but precise dosage control and safety of use of viral vectors make clinical application of this approach doubtful. Therefore, further new options, such as gene therapy or stem cell therapy, must be comprehensively studied and developed so as to make neurotrophin application more realistic in glaucoma treatment (52).

\section{Neuroprotection to counteract oxidative and nitrosative stress}

A number of studies confirmed the role of oxidative stress in the pathogenesis of glaucoma, especially primary open-angle glaucoma. Under normal conditions, there is an equilibrium between prooxidants and antioxidants. A disruption of this equilibrium causes increased generation of free oxygen radicals, which exceeds the capabilities of their deactivation and elimination. Accumulation of reactive oxygen species (ROS) contributes to the activation of processes that damage cells and lead to their death. A similar situation occurs in patients with 
glaucoma. In fact, in glaucomatous eyes, antioxidant deficiency $(58,59)$, an increase in the marker of DNA damage caused by oxidative stress - 8-oxo-2'deoxyguanosine(8-oxo2dG) (59), the presence of glutathione S-transferase antibodies (60), decreased plasma glutathione level (61) and increased lipid peroxidation products in blood plasma of patients with POAG (62) were demonstrated. Additionally, increased concentration of reactive oxygen species decreased cell membrane potential and reduced ATP production in the trabecular meshwork (TM) were described $(63,64)$. Deficiency of the mechanisms that reduce and eliminate ROS and the associated accumulation of free oxygen species damage the trabecular meshwork and lead to an increase in IOP and to the development of glaucomatous neuropathy $(65,66)$.

The best-studied enzymatic mechanisms protecting against oxidative stress are superoxide dismutase (SOD), catalase and glutathione peroxidase. Antioxidants that are not as well known but play an important role in counteracting ROS are thioredoxin (TRX), glutathione S-transferase and aldehyde dehydrogenase (67).

Theoretically, ROS inhibition and improvement of the defence systems could increase the viability of retinal ganglion cells. Such an effect was demonstrated in animal model studies where, after experimental damage to TM, overexpression of TRX limited RGC apoptosis despite high intraocular pressure (67).

In another study, the role of vitamin $\mathrm{E}$ in RGC protection was demonstrated. Dietary deficiency of vitamin $\mathrm{E}$ was associated with increased levels of lipid peroxidation products, which contributed to increased apoptosis of retinal ganglion cells (68).

A well-known potent antioxidant which may protect nerve cells from oxidative stress is coenzyme Q10 (CoQ10). Its functions are stabilisation of mitochondrial membrane potential, support of ATP synthesis and inhibition of ROS generation (69-71).

As demonstrated in a study conducted by Nakajima, CoQ10 protects retinal neurons from oxidative stress caused in vitro by hydrogen peroxide and in vivo by NMDA-induced excitotoxicity of glutamate (72). Moreover, CoQ10 prevented retinal damage caused by transient ischaemia induced by an acute increase in IOP (73).

The effect of antioxidants in the assessment of internal retinal layers and the optic nerve was analysed in a clinical trial in which eye drops containing coenzyme Q10 in combination with vitamin E were administered together with beta-blocker antiglaucoma eye drops to 22 glaucoma patients. In the 6th and 12th months of treatment, improved parameters of ERG and VEPs were obtained in the group of patients treated with topical eye drops with antioxidants in comparison with the control group treated with beta-blockers alone (74).

Ginkgo biloba extract (GBE) is another substance that raised interest as to its neuroprotective effect in glaucoma. It contains certain compounds, including polyphenol flavonoids, that are able to penetrate into mitochondria and prevent oxidative stress, thus protecting RGCs from destruction. Mitochondria are the energy reservoir of the cell; this is where ATP is produced, which is necessary for the normal functioning of retinal ganglion cells and the optic nerve $(66,75)$.

In a randomised clinical trial, improvement of visual field indices was obtained in 27 patients with normal tension glaucoma using oral GBE (76). Nevertheless, in another trial, no improvement was noted in contrast sensitivity and visual field parameters in NTG patients treated with GBE (77). Taking into account the chronic course of glaucoma, the duration of follow-up, which was 4 months, and the small group of patients enrolled in the study, the published data require further analyses.

Antioxidant activity is also displayed by other substances such as polyphenol flavonoids that occur in green tea, coffee, wine, and dark chocolate, anthocyanosides in blueberries, vitamins such as vitamin B1, and even melatonin (78). Nevertheless, there have been no studies that would clearly confirm the efficacy and safety of these compounds in glaucoma neuroprotection. Another open issue is the question of whether antioxidants are beneficial for all glaucoma patients or only in cases with low antioxidant reserves.

The evidence given in the literature indicates the possible effect of nitric oxide (NO) on the progression of retinal ganglion cell degeneration. In both studies, in an animal model of experimental glaucoma (79) as well as in patients with POAG (80), increased expression of nitric oxide synthase (NOS) was noted. Among the three isoforms of NOS, only NOS-2 has neurotoxic activity. Therefore, NOS-2 inhibitors such as aminoguanidine or N-nitro-L-arginine and other substances: cannabidiol (CBD), synthetic cannabinoids, tetrahydrocannabinol, and HU-211 were subjected to assessment. Reports on the study are inconclusive. According to some authors, the substances listed above have a neuroprotective effect $(81-84)$, but other investigators do not confirm the protective effect of NOS-2 inhibitors in glaucomatous neuropathy $(85,86)$. 
Neuroprotection to counteract vascular deregulation

Elevated intraocular pressure, low blood pressure and vascular deregulation have been proven to constitute risk factors of glaucomatous damage. Vascular deregulation is a pathological condition that interferes with normal autoregulation. Depending on needs, each tissue regulates its own blood perfusion independently from blood pressure. Perfusion pressure is the difference between blood pressure in arteries and blood pressure in veins. As to ocular perfusion, perfusion pressure refers to the difference between arterial blood pressure and intraocular pressure. Owing to the possibility of autoregulation, perfusion in the eye can be maintained at a stable level regardless of IOP and blood pressure fluctuations. Therefore, under conditions of abnormally functioning autoregulation, blood flow in the retina and the optic nerve is variable and depends on IOP and BP fluctuations. The role of intraocular pressure in the development of glaucomatous neuropathy is complex. Elevated IOP causes mechanical damage to the weakest structure in the eye, i.e. lamina cribrosa, and may also block the axoplasmic flow, which is discussed above, and finally, may lower ocular perfusion. On the other hand, when autoregulation is impaired, lowering arterial blood pressure - similarly to high IOP - contributes to decreased blood flow in the eye (87).

Apart from lowering intraocular pressure, the drugs used in glaucoma therapy may additionally improve blood perfusion in the eye (87). Such an effect is caused by carbonic anhydrase inhibitors (88). An improvement in ocular circulation was also noted in the case of latanoprost $(89,90)$.

Experimental studies in animal models initially suggested a neuroprotective effect of betaxolol, a selective beta-blocker, under retinal ischaemia conditions (91). Nevertheless, this has not been proven so far (92). On the other hand, possible inhibition by betaxolol of calcium influx into retinal cells through a direct effect on voltage-gated calcium or sodium channels has been suggested (93).

Among selective agonists of the alpha-2-adrenergic receptor whose presence has been demonstrated in ganglion cells and in the inner nuclear layer of the retina, brimonidine has been studied (94). Through direct interaction with the alpha-2-adrenergic receptor, brimonidine decreases glutamate accumulation and NMDA receptor blockade. Considering this mechanism of action, brimonidine was suggested to be able to prevent RGC death independently from IOP lowering $(95,96)$.

In randomised trials comparing the action of brimonidine with that of $0.5 \%$ timolol, results were presented in which brimonidine inhibited the progression of visual field defects and also reduced the rate of RNFL loss $(97,98)$.

Clear demonstration of the neuroprotective effect of anti-glaucoma medicines is a real challenge, posing difficulties in conduct and interpretation. It should be borne in mind that lowering of intraocular pressure, by itself, has a protective effect on RGCs and the optic nerve, but its efficacy is insufficient. as has been proven in practice. Hence the search for other substances, which, in combination with IOP-lowering products, would have a protective effect in both retinal and epiretinal areas.

\section{Stem cells in glaucoma neuroprotection}

Stem cells are now a subject of interest for scientists in practically every field of medicine. They have found particular appreciation in the context of treating neurodegenerative disorders, in view of their unlimited ability to independently renew and differentiate into every cell type. The unique properties of stem cells may prove useful in the treatment of glaucomatous neuropathy. One hypothesis assumes the use of stem cells that could replace lost retinal and optic nerve cells (99). Another approach would be their use for replacement or regeneration of trabecular meshwork cells, which would support the regulation of secretion and outflow of aqueous humour and thus greater IOP control (100).

Another approach to the use of stem cells is their transplantation as carriers of bioactive factors. An advantage of such a solution would be a local long-term activity of certain factors. A hypothesis was made that implantation of certain types of stem cells activates multiple neuroprotective pathways simultaneously through secretion of different factors (101). Delivery of various neurotrophic factors is the most commonly accepted mechanism through which the transplanted cells may modulate excitotoxicity. As has already been discussed, deprivation of neurotrophic factors is considered to be one of the basic pathophysiological mechanisms of RGC death in glaucoma.

In this respect, there are serious concerns about the potential generation of factors of unknown activity in addition to the desirable neurotrophic factor. Therefore, before stem cells are transplanted in clinical practice, it is necessary to identify and investigate all substances that may be produced by these carriers (102).

Another limitation is transplant survival. Prolonged survival is necessary to obtain continuous benefits from stem cell transplantation but is also associated with the risk of tumour develop- 
ment (103). Therefore, careful selection of stem cells through long-term follow-up and safety assessment will be necessary to ensure that the potential benefits of neuroprotection outweigh the risk of carcinogenesis.

Another issue is the induction of reactive gliosis in the retina as a consequence of stem cell transplantation. Inhibition of retinal fibrosis induced by stem cells is critical for transplantation success (104).

Although stem-cell therapy is a promising forward-looking neuroprotective approach in glaucoma treatment, it still has a long way to go in development terms, and we will have to wait for the results of clinical trials.

The pathophysiology of glaucomatous neuropathy is complex, and permanent damage of retinal ganglion cells and the optic nerve is caused by the overlapping of the aforementioned mechanisms. So far, the only known factor leading to the disease is intraocular pressure, and the treatment applied is targeted toward IOP reduction either by lowering aqueous humour secretion or by improving the function of the outflow pathways or creating new ones in the case of surgical treatment. Applied drug products, as well as laser and surgical techniques, have been improved over time, on the basis of new evidence for pathological mechanisms in glaucoma. One of the consequences of the search for the mechanism or mechanisms responsible for the development of glaucomatous neuropathy is the change of the definition and perception of the nosocomial entity in the context of neurodegeneration. Such an approach extended the possibilities of further studies with a broader view of glaucoma by exploring the pathophysiology of such degenerative disorders as Parkinson's disease or Alzheimer's disease. The search for the common denominator of pathological groups in both neurology and ophthalmology, but affecting the same nervous system, resulted in more focus on the use of neuroprotection in glaucoma treatment as adjunctive therapy to the existing antihypertensive treatment supported by research. So far, no drug with such activity has been recommended in pharmacological therapy of glaucoma. However, there is an increasing interest in citicoline, a substance known for many years.

\section{Citicoline and its neuroprotective effects}

Cytidine 5'-diphosphocholine (CDP-choline) or citicoline is an endogenous compound that is active in the pathway of cell membrane phospholipid biosynthesis (105). It was identified for the first time in the 1950s by Kennedy and collaborators, who described in their study that this phospho- rylated choline nucleotide was a precursor of phosphatidylcholine (106). One of the main effects of citicoline is stimulation of phospholipid synthesis in the central nervous system (CNS) $(107,108)$. The neuroprotective effect of CDP-choline, through prevention of phospholipase A2 (PLA2) activation, protects against an increase in the level of hydroxyl radicals and loss of cardiolipin (105), which together with phosphatidylcholine, constitutes the main ingredient of the inner mitochondrial membrane, playing an important role in the normal functioning of the respiratory chain. Citicoline raises the levels of various neurotransmitters and neuromodulators (106-110). An example is an increase in the level of sirtuin-1 (SIRT1), which appears to be of key neuroprotective importance in ischaemic states, particularly in cerebral ischaemia (107-111). Citicoline also increases the level of neurotransmitters in the central nervous system, such as dopamine (through increased activity of tyrosine hydroxylase and inhibition of dopamine reuptake), norepinephrine and serotonin, and serves as a choline donor in acetylcholine biosynthesis (107). Citicoline has a positive effect on glucose metabolism and microcirculation in central nervous system structures (108). Citicoline displays a tendency to lower elevated glutamate levels and contributes to the normalisation of decreased ATP level resulting from cerebral ischaemia (109-111). Citicoline has a very good safety profile, which has been evidenced in many clinical trials (108-121). Usually, the daily dose in humans is $500-2000 \mathrm{mg}$, i.e. $7-28 \mathrm{mg} / \mathrm{kg}$ in a person with average body weight $(70 \mathrm{~kg})$. After administration as a source of choline, citicoline is rapidly catabolised, and the products formed are then available for different biosynthesis pathways and are ultimately eliminated as carbon dioxide. In a large study assessing the safety of citicoline used orally for 2-9 weeks in 2,817 patients with Alzheimer's disease and vascular dementia (118), only $5 \%$ of study subjects reported drug-related adverse effects, mostly affecting the gastrointestinal tract and not requiring discontinuation of treatment.

The neuroprotective and neuromodulating effects of CDP-choline in acute and chronic ischaemic stroke, in neurodegenerative diseases (Alzheimer's disease - AD, Parkinson's disease $\mathrm{PD}$, glaucoma) or in pathologies resulting from the excitotoxic action of glutamate and amyloid toxicity were demonstrated in many experimental in vivo and in vitro studies (107-121). The results of clinical trials indicate possible efficacy of citicoline after its short-term use in acute ischaemic stroke, the evidence of which is an improved level of conscious- 
ness and disability evaluated on the basis of the specially modified Rankin scale (mRs) (110-113). At the experimental level, reduced cerebral infarction and oedema were reported. This led to an improvement in neurological deficits when citicoline was used alone or in combination with other factors (120). The results of an international randomised multi-centre placebo-controlled study (the ICTUS trial) involving 2,298 patients, in which there was no significant difference in recovery at 90 days after acute ischaemic stroke in patients treated with citicoline and placebo at a ratio of 1:1, raised controversies. It was difficult to obtain significant conclusions in that study as different sample sizes, multiple doses and several endpoints were used. In view of the unclear effect of recombinant tissue plasminogen activator (rt-Pa), the authors subsequently concluded that the ICTUS results suggested a positive effect of citicoline used in patients with acute ischaemic stroke who had not been treated with rt-PA (111).

The action of citicoline in Alzheimer's disease leads to reduced formation of beta-amyloid, which prevents the degradation of nerve cells and reduces the number of apoptotic cells (112). Improved cognitive functions, bioelectrical CNS activation and cerebral blood flow were demonstrated in $\mathrm{AD}$ patients (121). In addition, citicoline has a positive effect on memory, behaviour, global functioning and enhances focused attention $(108,121)$.

Stimulation of the dopaminergic system by citicoline may be responsible for the improvement of retinal and post-retinal visual pathways in visual impairment. This has been confirmed in studies $(116,119)$, that have demonstrated an improvement in visual acuity, contrast sensitivity, PERG parameters and shortening of P100 latency in VEP (116). A similar mechanism of improving the functioning of dopaminergic pathways contributes to the improvement of neurological symptoms in Parkinson's disease $(112,114)$.

Experimental studies suggested neuromodulating action and a protective role of citicoline on retinal ganglion cells in several mechanisms (Table 1). CDP-choline decreases the expression of NOS isoforms, counteracting nitrosative stress, exerts antiapoptotic action, and by increasing the retinal level of dopamine, prevents the loss of retinal nerve fibres. The neuroprotective effect of citicoline was confirmed in neurodegenerative disorders of the visual system in humans, such as glaucoma or nonarteritic ischaemic neuropathy. This was reflected in the results of electrophysiological examinations

Table 1 The table contains a listing of the mechanisms of neuroprotective action of citicoline relevant to glaucomatous neuropathy.

\begin{tabular}{|l|l|l|}
\hline $\begin{array}{c}\text { GLAUCOMA - } \\
\text { mechanism } \\
\text { of disease development }\end{array}$ & CITICOLINE - neuroprotection & \multicolumn{1}{c|}{ STUDY } \\
\hline Nitrosative stress & $\begin{array}{l}\text { Reduced isoforms of nitric oxide } \\
\text { synthase }\end{array}$ & $\begin{array}{l}\text { Park C. et al.: Neuroprotective effect of citicoline } \\
\text { against KA-induced neurotoxicity in the rat retina. } \\
\text { Exp. Eye Res. 81, 350-358 (2005). }\end{array}$ \\
\hline Neurotrophic factors & Effect imitating the BDNF factor & $\begin{array}{l}\text { Oshitari T. et al.: Effect of neurotrophic factors on } \\
\text { neuronal apoptosis and neurite regeneration in } \\
\text { cultured rat retinas exposed to high glucose. } \\
\text { Brain Res. 1346, 43-51 (2010). }\end{array}$ \\
\hline Inhibition of apoptosis & $\begin{array}{l}\text { Increased expression of Bcl-2 } \\
\text { inhibiting retinal apoptosis. } \\
\text { Reduced CNS expression of } \\
\text { activating apoptospase-3 }\end{array}$ & $\begin{array}{l}\text { Schuettauf F. et al.: 2006. Citicoline and lithium } \\
\text { rescue retinal ganglion cells following partial optic } \\
\text { nerve crush in the rat. Exp. EyeRes. 83, 1128-1134 } \\
\text { (2006). }\end{array}$ \\
\hline $\begin{array}{l}\text { Fiedorowicz M. et al.: CDP-choline (citicoline) } \\
\text { attenuates brain damage in a rat model of birth } \\
\text { asphyxia. Acta Neurobiol. Exp. (Wars) 68, 389-397 } \\
\text { (2008). }\end{array}$ \\
\hline Excitotoxicity & $\begin{array}{l}\text { Reduced glutamate level under } \\
\text { CNS hypoxaemia and hypoxia } \\
\text { conditions }\end{array}$ & $\begin{array}{l}\text { Matteucci A. et al.: Neuroprotective effects of } \\
\text { citicoline in in vitro models of retinal } \\
\text { neurodegeneration. Int. J. Mol. Sci. 15, 6286-6297 } \\
\text { (2014). }\end{array}$ \\
\hline $\begin{array}{l}\text { Mitochondrial } \\
\text { dysfunction }\end{array}$ & $\begin{array}{l}\text { Increased phosphocreatine, } \\
\text { ATP and cell membrane } \\
\text { ingredients }\end{array}$ & $\begin{array}{l}\text { Silveri M. et al.: Citicoline enhances frontal lobe } \\
\text { bioenergetics as measured by phosphorus magnetic } \\
\text { resonance spectroscopy. NMR Biomed. 21, 1066- } \\
\text { 1075 (2008). }\end{array}$ \\
\hline
\end{tabular}


(PERG, VEP) and visual field examinations assessing the improved activity of retinal and post-retinal visual pathways.

\section{Citicoline efficacy in glaucoma: clinical evidence}

The first reports on citicoline in the treatment of POAG were presented by Pecordi in 1989 (122). Together with his collaborators, he described the results of using intramuscular injections of citicoline in a group of 34 eligible patients, obtaining a $75 \%$ improvement of visual field parameters. The study was then continued over a 10-year follow-up period (123). The purpose of that study was to assess the effects of repeated cycles of citicoline intake by glaucoma patients (11 of 23 patients received $1 \mathrm{~g}$ of citicoline daily for 15 consecutive days, i.e. 1 cycle repeated every 6 months) to find out whether an improvement in retinal sensitivity translates, in the longer-term, to protective action of the substance as reflected in visual field examination results. The main efficacy variable was considered the worsening fraction of the visual field assessed on the basis of the non-perception area (NPA), a perimetric index obtained by means of Video Screen Perimetry (124). NPA may be considered an indirect measure of retinal sensitivity and is closely correlated with the MD (mean deviation) index of conventional automatic perimetry. A visual field was deemed to be worse (endpoint for the survival curve) when an increase of the NPA $>500 \mathrm{~mm} 2$ was found and confirmed in at least two consecutive examinations. The worsening fraction of the visual field was evidenced to be larger in the group of patients not treated with citicoline, i.e. in 5 of 12 patients, in comparison with the group treated with injections, in which visual field parameters worsened in only 2 patients. Patients treated with citicoline exhibited considerable improvement in retinal sensitivity (NPA reduction) at the first follow-up (1 year), which was maintained over the subsequent 9 years. It should be noted that intraocular pressure was lowered by topical antiglaucoma agents in all study subjects.

Subsequent reports presented a positive effect of citicoline treatment on the basis of assessment by electrophysiological methods: VEP and PERG. Both the ERG pattern as well as visual evoked potentials are valuable tests that enable thorough determination of the visual pathway's condition from its retinal origin, through post-retinal pathways, to cortical visual centres. Therefore, the study's authors used electrophysiology to present the actions of the investigated drug more precisely. A double-blind placebo-controlled study with 8 years of follow-up (125), included 30 patients ran- domised into 2 groups: one group of 15 persons was treated with citicoline (GC), while the remaining 15 persons received placebo (GP). The results were as follows. In all patients treated with citicoline, shortening of P100 latency in VEP and of P50 in PERG and an increase in amplitude of the respective waves were observed, with a reduction of the "retinocortical time" (RCT, the difference between VEP P100 latency and PERG P50 latency), which constitutes a measure of neural conduction in post-retinal visual pathways. During the 4-month wash-out, worsening of the VEP and PERG parameters was observed in comparison with the examination after the first dose, which was nevertheless significantly better than in the baseline examination. After the second pulse of citicoline treatment, both the latency and amplitude of P100 and P50 waves improved. The last examinations were performed after a second 4-month wash-out period. Finally, the P100 and P50 latency were significantly shorter, and the amplitude remained at the baseline level. Additionally, a correlation was found between electrophysiological changes and visual field examination results. An improvement of MD was obtained in all treated GC patients. Confirmation of the results of electrophysiological tests by visual field examination affords the clinician a more relaxed approach to electrophysiology, while nevertheless being a more exact and objective method. No changes in VEP and PERG were observed in the placebo group in the subsequent examinations versus the baseline one. The use of citicoline proved to be not only effective but also safe. In fact, no adverse drug reactions were obtained throughout the treatment period. An important endpoint was confirmation of the neuroprotective effect of citicoline, which inhibited glaucoma progression, but the treatment had to be repeated periodically in order to obtain a long-term effect. Another study quoted in several publications evaluated the efficacy of citicoline, administered in an oral form, in reducing glaucoma progression (126). The multi-centre prospective study included 41 POAG patients in whom disease progression was confirmed within the past 3 years based on worsening of visual field parameters (MD reduction by $1 \mathrm{~dB} /$ year). Oral treatment with citicoline was applied for 2 years in four 4-month cycles. An improvement in the visual field was noted as early as after the first cycle and was maintained throughout the study. The mean progression rate changed from $-1.1 \mathrm{~dB} /$ year (SD 0.7) before the treatment to $-0.15 \mathrm{~dB} /$ year at the end of the study. The difference in retinal sensitivity was statistically significant. Additionally, an average reduction of IOP by 
$1 \mathrm{mmHg} /$ year was observed, which also had an effect on glaucoma progression. The fact of more rapid visual field loss in patients with IOP $>15$ $\mathrm{mmHg}$ in comparison with IOP $<15 \mathrm{mmHg}$ was noted. The authors concluded that supplementation of citicoline as an oral solution could have a significant effect on delaying glaucoma progression and could enable better IOP control when combined with antihypertensive treatment.

Initially, citicoline was administered in the form of intramuscular injections. In 2003, Rejdak et al. published the results of their studies (127), in which they obtained an improvement of VEP parameters (shortening of P100 latency and a considerable increase in VEP amplitude) in patients with POAG by administering citicoline in oral form at a dose of $1 \mathrm{~g}$ daily with a 2 -week treatment-free interval. As demonstrated in further Italian studies (128), citicoline has equivalent efficacy regardless of the form (oral vs intramuscular injections) in which it was administered. Other authors confirmed the good effect of using the medicine in the oral form on the basis of electrophysiological examinations. It was also found that after discontinuation of treatment, an improvement in the investigated parameters was maintained for several months. Attempts were also made to use citicoline in the form of eye drops (129). Its neuroprotective effect was also confirmed in such a case. Nevertheless, it is of concern that, as a water-soluble substance, CDP-choline poorly penetrates through the retina, and only the addition of benzalkonium chloride (BAK) and hyaluronic acid can improve its penetration into the vitreous body. It is known that a glaucoma patient normally uses antihypertensive medicines in the form of eye drops, which are not neutral to the eye's surface. Hence, citicoline in the oral form, whose safety in systemic administration was confirmed in numerous studies, seems to be the best option in the adjunctive treatment of glaucoma.

\section{SUMMARY}

Glaucoma is a disease with a complex pathomechanism. The pharmacological treatment commonly applied, enabling reduction of intraocular pressure to the so-called "controlled" level, is insufficient in a certain group of patients in whom considerable disease progression is noted despite such intervention. Considering glaucomatous neuropathy as a type of neurodegeneration extended the possibilities of supporting antihypertensive pharmacological treatment with neuroprotective agents. This branch of conservative treatment gives hope for bet- ter management of the disease. In previous years, various compounds were proposed as adjunctive therapy in view of their possible neuroprotective activity. Apart from a few exceptions, these drugs failed clinical trials, despite a large amount of experimental evidence from animal models.

Citicoline acts on multiple aspects of glaucomatous neuropathy's pathogenesis. The potential neuromodulating and neuroprotective effects of citicoline were the subjects of effective studies conducted in patients with stroke, cognitive impairment and neurodegenerative diseases (Parkinson's disease and Alzheimer's disease). In addition to the above, the positive effects of citicoline were confirmed in many pathologies related to the visual system, e.g. amblyopia or non-arteritic ischaemic neuropathy of the optic nerve (25). The results of citicoline use in glaucoma are interesting. This endogenous substance, with a solid history of experimental and clinical studies, can be considered a very promising molecule for neuroprotective strategy in glaucoma patients.

\section{REFERENCES}

1. World Health Organization. Visual impairment and blindness: Fact Sheet No 282 2014. (accessed Sep 2014).

2. Tham Y.C., Li X., Wong T.Y., Quigley H.A., Aung T., Cheng CY.: Ophthalmology 121, 2081 (2014).

3. Quigley H.A., Broman A.T.: Br. J. Ophthalmol. 90, 262 (2006).

4. Casson R.J., Chidlow G., Ebneter A., Wood J.P., Crowston J., Goldberg I.: Clin. Exp. Ophthalmol. 40, 350 (2012).

5. Quigley H.A., Nickells R.W., Kerrigan L.A., Pease M.E., Thibault D.J., Zack D.J.: Ophthalmol. 36, 774 (1995).

6. Bizrah M., Dakin S.C., Guo L., Rahman F., Parnell M. et al.: BMC Bioinformatics 15, 169 (2014).

7. Agarwal R., Gupta S.K., Agarwal P., Saxena R., Agrawal S.S.: Indian J. Ophthalmol. 57, 257 (2009).

8. Almasieh M., Wilson A.M., Morquette B., Cueva Vargas J.L., Di Polo A.: Prog. Retin. Eye Res. 31, 152 (2012).

9. Yücel Y., Gupta N.: Prog. Brain Res. 173, 465 (2008).

10. Bogorodzki P., Piatkowska-Janko E., Szaflik J., Szaflik J.P., Gacek M., Grieb P.: PLoS One 9, e93682 (2014).

11. Parisi V.: Clin. Neurophysiol. 112, 351 (2001). 
12. Grieb P., Jünemann A., Rekas M., Rejdak R.: Front. Aging Neurosci. 8, 73 (2016).

13. Levy D.I., Lipton S.A.: Neurology 40, 852 (1990).

14. Sisk D.R., Kuwabara T.: Graefes Arch. Clin. Exp. Ophthalmol. 223, 250 (1985).

15. Wang R., Reddy P.H.: J. Alzheimers Dis. 57, 1041 (2017).

16. Sucher N.J., Lipton S.A., Dreyer E.B.: Vision Res. 37, 3483 (1997).

17. Aihara M., Chen Y.N., Uchida S., Nakayama M., Araie M.: Molecular Vision 20, 606 (2014).

18. Brooks D.E., Garcia G.A., Dreyer E.B., Zurakowski D., Franco-Bourland R.E.: Am. J. Vet. Res. 58, 864 (1997).

19. Dreyer E.B., Zurakowski D., Schumer R.A., Podos S.M., Lipton S.A.: Arch. Ophthalmol. 114, 299 (1996).

20. Salt T.E., Cordeiro M.F.: Eye (Lond) 20,730 (2006).

21. Osborne N.N., Ugarte M., Chao M., Chidlow G., Bae J.H. et al.: Surv. Ophthalmol. 43 (Suppl 1), S102 (1999).

22. Miguel-Hidalgo J.J., Alvarez X.A., Cacabelos R., Quack G.: Brain Res. 958, 210 (2002).

23. Danesh-Meyer H.V., Levin L.A.: Am. J. Ophthalmol. 148, 186 (2009).

24. Lagrèze W.A., Knörle R., Bach M., Feuerstein T.J.: Invest. Ophthalmol. Vis. Sci. 39, 1063 (1998).

25. Hare W.A., Wolde Mussie E., Lai R.K., Ton H., Ruiz G. et al.: Invest. Ophthalmol. Vis. Sci. 45, 2625 (2004).

26. Gabelt B.T., Rasmussen C.A., Tektas O.Y., Kim C.B., Peterson J.C. et al.: Investig. Ophthalmol. Vis. Sci. 53, 2368 (2012).

27. Fang J.H., Wang X.H., Xu Z.R., Jiang F.G.: BMC Neurosci. 11, 31 (2010).

28. Pang Y.P., Quiram P., Jelacic T., Hong F., Brimijoin S.: J. Biol. Chem. 271, 23646 (1996).

29. Wang H., Carlier P.R., Ho W.L., Wu D.C., Lee N.T., Li C.P. et al.: Neuroreport. 10, 789 (1999).

30. Li W., Lee N.T., Fu H., Kan K.K., Pang Y. et al.: Neuroreport. 17, 471 (2006).

31. Blanpied T.A., Boeckman F.A., Aizenman E., Johnson J.W.: J. Neurophysiol. 77, 309 (1997).

32. Crish S.D., Calkins D.J.: Neuroscience 176, 1 (2011).

33. Takahashi K., Lam T.T., Edward D.P., Buchi E.R., Tso MOM.: Arch. Ophthalmol. 110, 862 (1992).

34. Mayama C.: Eur. J. Pharmacol. 739, 96 (2013).

35. Sawada A., Kitazawa Y., Yamamoto T., Okabe I., Ichien K.: Ophthalmology 103, 283 (1996).
36. Koseki N., Araie M., Yamagami J., Shirato S., Yamamoto S.: J. Glaucoma. 8, 117 (1999).

37. Koseki N., Araie M., Tomidokoro A., Nagahara M., Hasegawa T. et al.: Ophthalmology 115, 2049 (2008).

38. Cheung L.T.Y., Manthey A.L., Lai J.S.M., Chiu K.: Front Neurosci. 11, 648 (2017).

39. Iwase A., Tomidokoro A., Leung C., Zeitz O., Vingrys A. et al.: Ocular Blood Flow. in Glaucoma, p. 59, Kugler Publications, Amsterdam 2009.

40. Minckler D.S., Bunt A.H., Johanson G.W.: Invest. Ophthalmol. Vis. Sci. 16, 426 (1977).

41. Anderson D.R., Hendrickson A.: Invest. Ophthalmol. Vis. Sci. 13, 771 (1974).

42. Quigley H.A., McKinnon S.J., Zack D.J., Pease M.E., Kerrigan-Baumrind L.A. et al.: Invest. Ophthalmol. Vis. Sci. 41, 3460 (2000).

43. Pease M.E., McKinnon S.J., Quigley H.A., Kerrigan-Baumrind L.A., Zack D.J.: Invest. Ophthalmol. Vis. Sci. 41, 764 (2000).

44. Domenici L., Origlia N., Falsini B., Cerri E., Barloscio D. et al.: PLoS One 10, 1371 (2014).

45. Bonnet D., Garcia M., Vecino E., Lorentz J.G., Sahel J., Hicks D.: Brain Res. 1007, 142 (2004).

46. Chen H., Weber A.J.: Invest. Ophthalmol. Vis. Sci. 42, 966 (2001).

47. Pietrucha-Dutczak M., Smedowski A., Liu X., Matuszek I., Varjosalo M., Lewin-Kowalik J.: Sci. Rep. 10, 1038 (2017).

48. Sawai H., Clarke D.B., Kittlerova P., Bray G.M., Aguayo A.J.: J. Neurosci. 16, 3887 (1996).

49. Shpak A.A., Guekht A.B., Druzhkova T.A., Kozlova K.I., Gulyaeva N.V.: Mol. Vis. 23, 799 (2017).

50. Cheng L., Sapieha P., Kittlerová P., Hauswirth W.W., Di Polo A.: J. Neurosci. 22, 3977 (2002).

51. Checa-Casalengua P., Jiang C., Bravo-Osuna I., Molina-Martínez I.T., Young M.J., HerreroVanrell R.: J. Control. Release 156, 92 (2011).

52. Doozandeh A., Yazdani S.: J. Ophthalmic Vis. Res.: 11, 209 (2016).

53. Zhang K., Hopkins J.J., Heier J.S., Halperin L.S. et al.: Proc. Natl. Acad. Sci. U S A. 108, 6241 (2011).

54. Thanos S., Bähr M., Barde Y.A., Vanselow J.: Eur. J. Neurosci. 1, 19 (1989).

55. Mey J., Thanos S.: Brain Res.: 602, 304 (1993).

56. Lambiase A., Aloe L., Centofanti M., Parisi V., Báo S.N. et al.: Proc. Natl. Acad. Sci. U S A 106, 13469 (2009).

57. Weise J., Isenmann S., Klöcker N., Kügler S., Hirsch S. et al.: Neurobiol. Dis. 7, 212 (2000). 
58. Ferreira S.M., Lerner S.F., Brunzini R., Evelson P.A., Llesuy S.F.: Am. J. Ophthalmol. 137, 62 (2004).

59. Goyal A., Srivastava A., Sihota R., Kaur J.: Curr. Eye Res. 39, 823 (2014).

60. Yang J., Tezel G., Patil R.V., Romano C., Wax M.B.: Invest. Ophthalmol. Vis. Sci. 42, 1273 (2001).

61. Gherghel D., Griffiths H.R., Hilton E.J., Cunliffe I.A., Hosking S.L.: Invest. Ophthalmol. Vis. Sci. 46, 877 (2005).

62. Yildirim O., Ates N.A., Ercan B., Muslu N., Unlü A. et al.: Eye (Lond) 19, 580 (2005).

63. He Y., Leung K.W., Zhang Y.H., Duan S., Zhong X.F. et al.: Invest. Ophthalmol. Vis. Sci. 49, 1447 (2008).

64. Kanamori A., Catrinescu M.M., Kanamori N., Mears K.A., Beaubien R., Levin L.A.: Brain 133, 2612 (2010).

65. Saccà S.C., Gandolfi S., Bagnis A., Manni G., Damonte G. et al.: Ageing Res. Rev. 29, 26 (2016).

66. Saccà S.C., Pascotto A., Camicione P., Capris P., Izzotti A.: Arch. Ophthalmol. 123, 458 (2005).

67. Caprioli J., Munemasa Y., Kwong J.M., Piri N.: Trans. Am. Ophthalmol. Soc. 107, 161 (2009).

68. Ko M.L., Peng P.H., Hsu S.Y., Chen C.F.: Curr. Eye Res. 35, 842 (2010).

69. Forsmark-Andrée P., Lee C.P., Dallner G., Ernster L.: Free Radic. Biol. Med. 22, 391 (1997).

70. McCarthy S., Somayajulu M, Sikorska M, Borowy-Borowski H, Pandey S.: Toxicol. Appl. Pharmacol. 201, 21 (2004).

71. Davis B.M., Tian K., Pahlitzsch M., Brenton J., Ravindran N. et al.: Mitochondrion 36, 114 (2017).

72. Nakajima Y., Inokuchi Y., Nishi M., Shimazawa M., Otsubo K., Hara H.: Brain Res. 1226, 226 (2008).

73. Nucci C., Tartaglione R., Cerulli A., Mancino R., Spanò A. et al.: Int. Rev. Neurobiol. 82, 397 (2007).

74. Parisi V., Centofanti M., Gandolfi S., Marangoni D., Rossetti L. et al.: J. Glaucoma 23, 391 (2014).

75. Eckert A., Keil U., Scherping I., Hauptmann S., Müller W.E.: Ann. NY Acad. Sci. 1056, 474 (2005).

76. Quaranta L., Bettelli S., Uva M.G., Semeraro F., Turano R., Gandolfo E.: Ophthalmology 110, 359 (2003).
77. Guo X., Kong X., Huang R., Jin L., Ding X. et al.: Invest. Ophthalmol. Vis. Sci. 55, 110 (2014).

78. Mozaffarieh M., Grieshaber M.C., Orgül S., Flammer J.: Surv. Ophthalmol. 53, 479 (2008).

79. Siu A.W., Leung M.C., To C.H., Siu F.K., Ji J.Z., So K.F.: Exp. Eye Res. 75, 401 (2002).

80. Liu B., Neufeld A.H.: Glia 30, 178 (2000).

81. Jha M.K., Seo M., Kim J.H., Kim B.G., Cho J.Y., Suk K.: Biochim. Biophys. Acta. 1834, 2418 (2013).

82. Geyer O., Almog J., Lupu-Meiri M., Lazar M., Oron Y.: FEBS Lett. 374, 399 (1995).

83. Marsicano G., Moosmann B., Hermann H., Lutz B., Behl C.: J. Neurochem. 80, 448 (2002).

84. Yoles E., Belkin M., Schwartz M.: J. Neurotrauma. 13, 49 (1996).

85. Pang I.H., Johnson E.C., Jia L., Cepurna W.O., Shepard A.R. et al.: Invest. Ophthalmol. Vis. Sci. 46, 1313 (2005).

86. Libby R.T., Howell G.R., Pang I.H., Savinova O.V., Mehalow A.K. et al.: BMC Neurosci. 8, 108 (2007).

87. Mozaffarieh M., Flammer J.: Curr. Opin. Pharmacol. 13, 43 (2013).

88. Chandra S., Muir E.R., Deo K., Kiel J.W., Duong T.Q.: Invest. Ophthalmol. Vis. Sci. 57, 826 (2016).

89. Boltz A., Schmidl D., Weigert G., Lasta M., Pemp B. et al.: Invest. Ophthalmol. Vis. Sci. 52, 4410 (2011).

90. McKibbin M., Menage M.J.: Eye (Lond) 13, 31 (1999).

91. Osborne N.N., DeSantis L., Bae J.H., Ugarte M., Wood J.P. et al.: Exp. Eye Res. 69, 331 (1999).

92. Hirooka K., Kelly M.E., Baldridge W.H., Barnes S.: Exp. Eye Res. 70, 611 (2000).

93. Melena J., Stanton D., Osborne N.N.: Graefes Arch. Clin. Exp. Ophthalmol. 239, 522 (2001).

94. Bylund D.B., Chacko D.M.: Invest. Ophthalmol. Vis. Sci. 40, 2299 (1999).

95. Donello J.E., Padillo E.U., Webster M.L., Wheeler L.A., Gil D.W.: J. Pharmacol. Exp. Ther. 296, 216 (2001).

96. Kalapesi F.B., Coroneo M.T., Hill M.A.: Br. J. Ophthalmol. 89, 758 (2005).

97. Tsai J.C., Chang H.W.: J. Ocul. Pharmacol. Ther. 21, 475 (2005).

98. Krupin T., Liebmann J.M., Greenfield D.S., Ritch R., Gardiner S.: Am. J. Ophthalmol. 151, 671 (2011).

99. Johnson T.V., Bull N.D., Martin K.R.: Expert Rev. Ophthalmol. 6, 165 (2011). 
100. Du Y., Yun H., Yang E., Schuman J.S.: Invest. Ophthalmol. Vis. Sci. 54, 1450 (2013).

101. Plant G.W., Harvey A.R., Leaver S.G., Lee S.V.: Exp. Neurol. 229, 99 (2011).

102. Greco S.J., Rameshwar P.: Biologics 2, 699 (2008).

103. Reya T., Morrison S.J., Clarke M.F., Weissman I.L.: Nature 414, 105 (2001).

104. Tassoni A., Gutteridge A., Barber A.C., Osborne A., Martin K.R.: Stem Cells 33, 3006 (2015).

105. Saver J.L.: Rev. Neurol. Dis. 5, 167 (2008).

106. Weiss S.B., Smith S.W., Kennedy E.P.: J. Biol. Chem. 231, 53 (1958).

107. Martinet M., Fonlupt P., Pacheco H.: Arch. Int. Pharmacodyn. Ther. 239, 52 (1979).

108. Grieb P.: CNS Drugs 28, 185 (2014).

109. Grieb P., Rejdak R.: J. Neurosci. Res. 67, 143 (2002).

110. Alvarez-Sabín J., Román G.C.: Brain Sci. 3, 1395 (2013).

111. Dávalos A., Alvarez-Sabín J., Castillo J., Díez-Tejedor E., Ferro J. et al.: Lancet 380, 349 (2012).

112. Cacabelos R., Caamańo J., Gómez M.J., Fernández-Novoa L., Franco-Maside A., Alvarez X.A.: Ann. N. Y. Acad. Sci. 777, 399 (1996).

113. Alvarez X.A., Sampedro C., Lozano R., Cacabelos R.: Methods Find Exp. Clin. Pharmacol. 21, 535 (1999).

114. Agnoli A., Ruggieri S., Denaro A., Bruno G.: Neuropsychobiology 8, 289 (1982).

115. Pawar P.V., Mumbare S.S., Patil M.S., Ramakrishnan S.: J. Ophthalmol. 62, 124 (2014).

116. Parisi V., Coppola G., Ziccardi L., Gallinaro G., Falsini B.: Eur. J. Neurol. 15, 465 (2008).
117. Tham Y.C., Li X., Wong T.Y., Quigley H.A., Aung T., Cheng C.Y.: Ophthalmology 121, 2081 (2014).

118. Lozano F.R.: Arzneimittelforschung 33, 1073 (1983).

119. Porciatti V., Schiavi C., Benedetti P., Baldi A., Campos E.C.: Curr. Eye Res. 17, 141 (1998).

120. Gutiérrez-Fernández M., Rodríguez-Frutos B., Fuentes B., Vallejo-Cremades M.T., AlvarezGrech J. et al.: Neurochem. Int. 60, 310 (2012).

121. Alvarez X.A., Mouzo R., Pichel V., Pérez P., Laredo M. et al.: Methods Find. Exp. Clin. Pharmacol. 21, 633 (1999).

122. Pecori Giraldi J.,Virno M., Covelli G., Grechi G., Di Gregorio F.: Int. Ophthalmol. 13, 109 (1989).

123. Virno M., Pecori-Giraldi J., Liguori A., De Gregorio F.: Acta Ophthalmol. Scand. Suppl. 232, 56 (2000).

124. Accornero N., Berardelli A., Cruccu G., Manfredi M.: Arch. Ophthalmol. 102, 40 (1984).

125. Parisi V.: Doc. Ophthalmol. 110, 91 (2005).

126. Ottobelli L., Manni G.L., Centofanti M., Iester M., Allevena F., Rossetti L.: Ophthalmologica 229, 219 (2013).

127. Rejdak R., Toczołowski J., Kurkowski J., Kaminski M.L., Rejdak K. et al.: Med. Sci. Monit. 9, PI24 (2003).

128. Parisi V., Coppola G., Centofanti M., Oddone F., Angrisani A.M. et al.: Prog. Brain Res. 173, 541 (2008).

129. Parisi V., Centofanti M., Ziccardi L., Tanga L., Michelessi M. et al.: Graefes Arch. Clin. Exp. Ophthalmol. 253, 1327 (2015).

Received: 2.12.2018 